\title{
The first decade of advanced cell therapy clinical trials using perinatal cells (2005-2015)
}

\author{
Pedro S Couto1, Alexey Bersenev² \& Frances Verter ${ }^{*}, 1$ \\ ${ }^{1}$ Parent's Guide to Cord Blood Foundation, Brookeville, MD 20833, USA \\ ${ }^{2}$ Cell Therapy Laboratory at Yale-New Haven Hospital, Yale University, CT 06520, USA \\ * Author for correspondence: fverter@his.com
}

\begin{abstract}
Aim: The first review of advanced cell therapy trials with perinatal cells. Materials \& methods: We compiled 281 clinical trials of advanced cell therapy with perinatal cells that were registered in 2005-2015. Results: The most common cell source in these trials is cord blood, but the cell type that provides the mechanism of action in the majority of trials is mesenchymal stem/stromal cells. We analyze trends among the 15 parameters we compiled for these trials. Conclusion: Advanced cell therapy with perinatal cells is a new field that covers a wide range of diagnoses but where most of the trials are early Phase. Researchers in different countries tend to work with a preferred cell source and cell type.
\end{abstract}

First draft submitted: 27 April 2017; Accepted for publication: 3 August 2017; Published online: 15 November 2017

Keywords: cell therapy $\bullet$ clinical trial $\bullet$ cord blood $\bullet$ perinatal cells

It is by now well established that all of the blood and tissues once considered merely the 'after birth' are rich sources of stem and progenitor cells [1-16]. The term 'perinatal' refers to 'around the time of birth'. Sources of perinatal cells include the umbilical cord blood, the umbilical blood vessels, the Wharton's jelly matrix of the umbilical cord, the amniotic membrane, the amniotic fluid and the entire placenta. While perinatal stem cells are classified as adult stem cells, they demonstrate markers that are intermediate between traditional sources of adult stem cells and embryonic stem cells [14-16].

The most well-known perinatal cell type is perhaps the hematopoietic stem cells (HSC) in umbilical cord blood $[1,2]$. The tissue of the umbilical cord, also known as Wharton's jelly, is a rich source of mesenchymal stem cells (MSC), with the cell density highest around the blood vessels in the cord [3-5]. The amniotic membrane that sheaths the placenta and umbilical cord lining yields a unique cell population that is a mixture of MSC and epithelial stem cells [6-8]. The placenta, chorion, amnion and even amniotic fluid are all rich sources of stem and progenitor cells, with somewhat different populations in each of these tissues [9-13]. We refer to all of these populations of stem and progenitor cells collectively as 'perinatal cells' [14-16].

The stem cells in umbilical cord blood have been used as a graft source for HSC transplants since $1988[17,18]$ and to date over 35,000 cord blood transplants have been performed worldwide [19]. However, the use of perinatal stem cells for therapeutic applications other than hematopoietic reconstitution has only become a field of its own within the past decade. In the case of regenerative medicine with cord blood, the first patient was an infant born with anoxic brain injury in September 2004 who received her autologous cord blood stem cells in February 2005. Her cord blood had been stored with the private bank Cord Blood Registry and she was treated by Dr Kurtzberg at Duke University under a compassionate use exemption [20]. Since then, the use of cord blood for acquired neurological disorders in infants has become a growing field. Moreover, increasing numbers of researchers have explored other novel applications of stem and progenitor cells from other perinatal sources [14-16]. Hence, the time has come for a retrospective of the past decade of clinical trials that conduct advanced cell therapies with cells from perinatal sources.

This paper analyzes a complete set of international databases of clinical trials registered over the years 2005-2015 that used cells from perinatal sources for advanced cell therapy. The goal of this endeavor is to gain an overview of what types of therapies are being developed with stem and progenitor cells from perinatal sources, how far along these therapies have come, and what are the demographics of how clinicians in different countries are funding and 
Box 1. Inclusion and exclusion criteria for clinical trials analyzed.

- Exclude hematopoietic stem and progenitor cell transplants (HSCT) for homologous reconstitution of the blood and immune system following chemotherapy for blood diseases and malignancies

- Include HSCT that use unmanipulated cells for nonhomologous use

- Include HSCT that use expanded and/or manipulated cells for homologous use

- Include all therapies that do not violate the above criteria in which cells are administered with the aim to engraft, repair or promote healing of tissues; this terminology has been used as the definition of 'regenerative medicine' $[23,24]$

- Include immune therapy where cells are administered to trigger the action of other immune cells

- Include tissue engineering where a matrix is seeded with cells

- Include gene therapy where cells are genetically modified to repair/modify local tissues

- Include registered trials that terminated or that only enrolled a patient and then closed. These may be considered failed trials, but our search strategy is to include all trials; we do not select only the currently open trials or only the trials that resulted in publications

- Exclude relevant studies which did not register as clinical trials. Again, our search strategy is to include all registered trials within our time frame. Possible reasons why an important study was not a registered trial include: trial registration is voluntary in the country where the study was conducted, or the trial was Phase I, or the patients were treated under a compassionate use exemption

- Exclude trials of platelet-rich plasma alone, because under US FDA regulations platelet-rich plasma is not considered to be cell therapy [25]

- Among qualifying advanced cell therapies holding viable cells, include both in vivo cell therapy and ex vivo therapy with extracorporeal devices that hold cells

- Exclude all cell products in which the cells are not viable

conducting research with perinatal cells. This paper is both the first cumulative review of advanced cell therapy trials with perinatal cells, as well as the first analysis that tracks perinatal trials by year of trial registration.

\section{Methodology}

In this study we compile all clinical trials registered between 2005 and 2015 in which perinatal cells are used for advanced cell therapies. Within this methodology section we present our definitions for 'perinatal cells', 'advanced cell therapy' and 'perinatal cell types'. Finally we describe our strategy of searching for and compiling clinical trials.

As we noted in the introduction, we adopt the standard definition for 'perinatal cells', one which is applied consistently in the literature and can be reviewed in books of the title "Perinatal Stem Cells" [14-16].

We define 'advanced cell therapy' trials as all therapies in which cells are more than minimally manipulated, or their action is not homologous. Our definition of advanced cell therapies is aligned with the EMA definition of advanced therapy medicinal products [21] and consistent with the US FDA definition of Section 351 'Human Cells, Tissues and Cellular- and Tissue-Based Products' [22]. Consequently, our compilation of clinical trials has the inclusions and exclusions detailed in Box 1.

Within the context of advanced cell therapy, most clinical trials with cells of perinatal origin tend to rely on the action of a particular cell type; we found that less than ten percent of the trials in this study utilized multiple cell types. In Box 2, we define the cell types that will be referenced throughout this paper.

Finally we describe our method of compiling cell therapy clinical trials. As background, we note that in recent years a new field has blossomed in which researchers compile and analyze databases of cell therapy clinical trials. These projects span a variety of techniques: researchers that compile trials from trial registries, researchers that search publications and work backwards to cited trials, researchers that focus on only a specific cell type or a specific indication for use and researchers that publish in journals versus researchers that present their results on websites. A summary of all published trial compilations is available on CellTrials.org [30]. The only previous study with a perinatal focus was a compilation of cord blood trials [31] which began from published papers and searched backwards to find their underlying trials, thereby identifying 47 trials. We do not compare our results to that study because our search strategy is to identify all trials, not only the ones that resulted in publications.

We searched for clinical trials of advanced cell therapies in a dozen international trial registries, which are listed in Table 1 in order of the year that they were founded. The majority of researchers who compile clinical trials rely solely on ClinicalTrials.gov. The US registry ClinicalTrials.gov is one of the oldest registries of clinical trials, and currently over half the listed studies on ClinicalTrials.gov are located outside the USA [32]. Nonetheless, the 
Box 2. Cell types used in clinical trials analyzed.

- Cord blood unmanipulated: Trials that rely on the action of unmanipulated cord blood cells, with no other cell source. We include therapies in which cord blood undergoes mononuclear cell enrichment or red blood cell depletion in the category of unmanipulated cells because these are minimal manipulations that can be performed at the point of care. In order to be included in this study of advanced cell therapy the cells must be performing a nonhomologous action. Hence, this category of trial can also be called cord blood regenerative medicine, either autologous or allogeneic $[23,24]$

- Cord blood manipulated: Trials that rely on the action of manipulated cord blood cells with no cell source in addition to cord blood. Most often in these trials the manipulated cord blood is given together with unmanipulated cord blood in a stem cell transplant. Examples of manipulated cell types include, but are not limited to, expanded cord blood progenitors, natural killer cells, cytotoxic T lymphocytes or oligodendrocytes (DUOC-01) [26]

- Cord blood MSC: Trials that rely on the action of MSC derived from cord blood with no other cell source

- Cord tissue MSC: Trials that rely on the action of MSC derived from umbilical cord tissue, also known as Wharton's jelly, with no other cell source

- Placenta MSC: Trials that rely on the action of MSC derived from the placenta, with no other cell source

- Other perinatal MSC: Trials that rely on the action of MSC derived from other perinatal tissues or from more than one perinatal source

- Other perinatal cells: Trials that rely on perinatal cells that do not fit any of the above categories. At present this category includes trials with epithelial stem cells from the amniotic membrane that sheaths the placenta and umbilical cord lining $[8,27]$. It also includes trials with blood perfused from the placenta, because the immunological behavior of this blood is distinct from cord blood [28,29]

- Multiple sources: These are trials in which one type of perinatal cells are combined with another cell type, perinatal or not. Some examples are cord blood and cord tissue used together, or cord blood and bone marrow together

MSC: Mesenchymal stem/stromal cells.

\section{Table 1. Clinical trial registries searched.}

\begin{tabular}{|c|c|c|}
\hline Clinical trial registry & Year launched & Ref. \\
\hline $\begin{array}{l}\text { Japan University hospital Medical Information } \\
\text { Network Clinical Trial Registry (UMIN-CTR) }\end{array}$ & (1997) & [33] \\
\hline ClinicalTrials.gov & $(2000)$ & [34] \\
\hline $\begin{array}{l}\text { Japan Medical Association Clinical Trial Registry } \\
\text { (JMA-CTR) }\end{array}$ & $(2003)$ & [35] \\
\hline EU Clinical Trials Register (EudraCT) & (2004) & [36] \\
\hline Chinese Clinical Trial Registry (ChiCTR) & (2005) & [37] \\
\hline $\begin{array}{l}\text { WHO International Clinical Trials Registry Platform } \\
\text { (ICTRP) }\end{array}$ & (2005) & [38] \\
\hline Netherlands Trial Register (NTR) & (2005) & [39] \\
\hline $\begin{array}{l}\text { Australian New Zealand Clinical Trial Registry } \\
\text { (ANZCTR) }\end{array}$ & (2007) & [40] \\
\hline Clinical Trials Registry-India (CTRI) & (2007) & [41] \\
\hline German Clinical Trials Register (DRKS) & (2008) & [42] \\
\hline Iranian Registry of Clinical Trials (IRCT) & (2008) & [43] \\
\hline $\begin{array}{l}\text { Clinical Research Information Service from South } \\
\text { Korea (CRiS) }\end{array}$ & (2010) & [44] \\
\hline
\end{tabular}

burgeoning growth of cell therapy and the establishment of clinical trial registries in additional countries have rendered the ClinicalTrials.gov registry an incomplete resource. During the 5 years (2011-2015), we find that 20\% of all advanced cell therapy clinical trials are not registered in ClinicalTrials.gov [30].

To capture all the perinatal cell therapy clinical trials we searched each registry by the following keywords: 'cord blood', 'umbilical cord', 'umbilical', 'cord', 'placenta', 'chorion', 'amnion', 'amniotic', 'perinatal', 'umbilical tissue' and 'Wharton's jelly'. Secondary ID's were also collected in order to eliminate any double entries of clinical trials in more than one registry. When manufacturers include viable perinatal cells as part of a therapeutic product or 


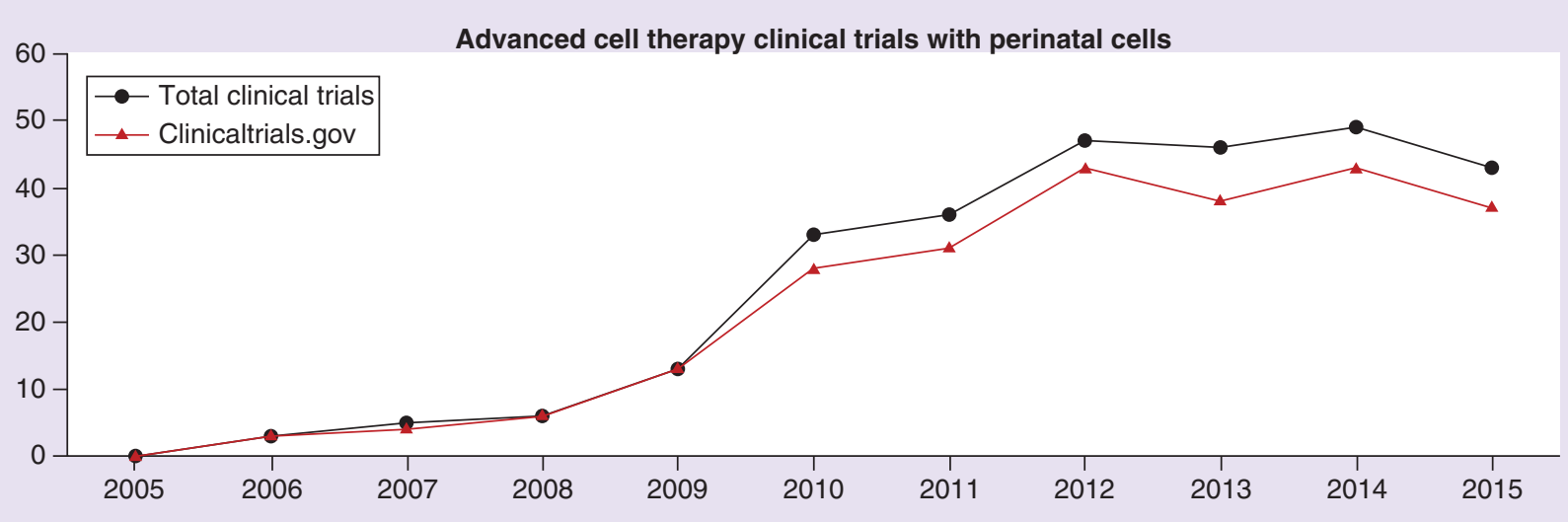

Figure 1. Number of advanced cell therapy clinical trials using perinatal cells registered per year. The black line is the total number of trials and the red line is the trials that are listed in ClinicalTrials.gov. When a trial was posted to more than one registry, for the purposes of this graph the registration on ClinicalTrials.gov was considered primary.

Table 2. Number of advanced cell therapy clinical trials using perinatal cells registered per year, divided by the source of the cells.

\begin{tabular}{|c|c|c|c|c|c|c|c|c|c|c|c|c|}
\hline \multirow[t]{2}{*}{ Cell source } & \multicolumn{12}{|c|}{ Trials/year } \\
\hline & 2005 & 2006 & 2007 & 2008 & 2009 & 2010 & 2011 & 2012 & 2013 & 2014 & 2015 & Total \\
\hline $\begin{array}{l}\text { Cord } \\
\text { blood }\end{array}$ & 0 & 2 & 3 & 3 & 10 & 12 & 15 & 21 & 26 & 18 & 12 & 122 \\
\hline Cord tissue & - & - & - & 1 & 0 & 13 & 13 & 18 & 8 & 16 & 23 & 92 \\
\hline $\begin{array}{l}\text { Other } \\
\text { perinatal }\end{array}$ & - & 1 & 1 & 1 & 2 & 3 & 3 & 4 & 4 & 12 & 6 & 37 \\
\hline $\begin{array}{l}\text { Multiple } \\
\text { sources }\end{array}$ & 0 & 0 & 1 & 1 & 1 & 5 & 5 & 4 & 8 & 3 & 2 & 30 \\
\hline Total & 0 & 3 & 5 & 6 & 13 & 33 & 36 & 47 & 46 & 49 & 43 & 281 \\
\hline
\end{tabular}

medical device, often their clinical trials only use the name of the product or device and never mention the perinatal keywords. Hence, in order to find all commercial applications of perinatal cells, keyword searches alone are not sufficient, it is necessary to conduct a preliminary investigation to identify the products and devices.

For each clinical trial in our final database, we collected the following 15 parameters if possible: clinical trial data (year registered, trial ID, country, Phase, status), cell data (cell type, cell source, mode of delivery, cell dose), patient data (diagnosis, age group, cell donor relationship, trial target enrollment) and sponsor data (source of funding, sponsor name if industry related). In a given year, we include all trials that were registered that year that meet our search criteria, regardless of trial status or projected completion date. Statistical data analysis was performed in Microsoft Office Excel.

\section{Results \& discussion}

Based on keyword hits, we found 19,422 candidate trials in the 12 searched trial registries that were registered between the years 2005-2015. Each trial was reviewed by a scientist, and trials with debatable status were reviewed by two or three scientists. The final number of clinical trials that met our criteria for inclusion in this study of advanced cell therapy with perinatal cells was 281 trials between the years 2005 and 2015. Figure 1 plots all our trials versus trials in ClinicalTrials.gov for the years 2005-2015. Over the course of the decade a gap appears between these two groups and grows wider, so that cumulatively $15 \%$ of our trials of advanced cell therapy with perinatal cells are not registered in ClinicalTrials.gov.

Table 2 and Figure 2 show the number of trials registered per year when characterized by the perinatal source of the cells. Each trial was attributed to one of the following categories of cell source: cord blood, cord tissue, other perinatal sources or multiple sources. The total number of trials in each source group is 122 cord blood, 92 umbilical cord tissue, 37 for other perinatal sources and 30 trials with multiple sources where at least one source 


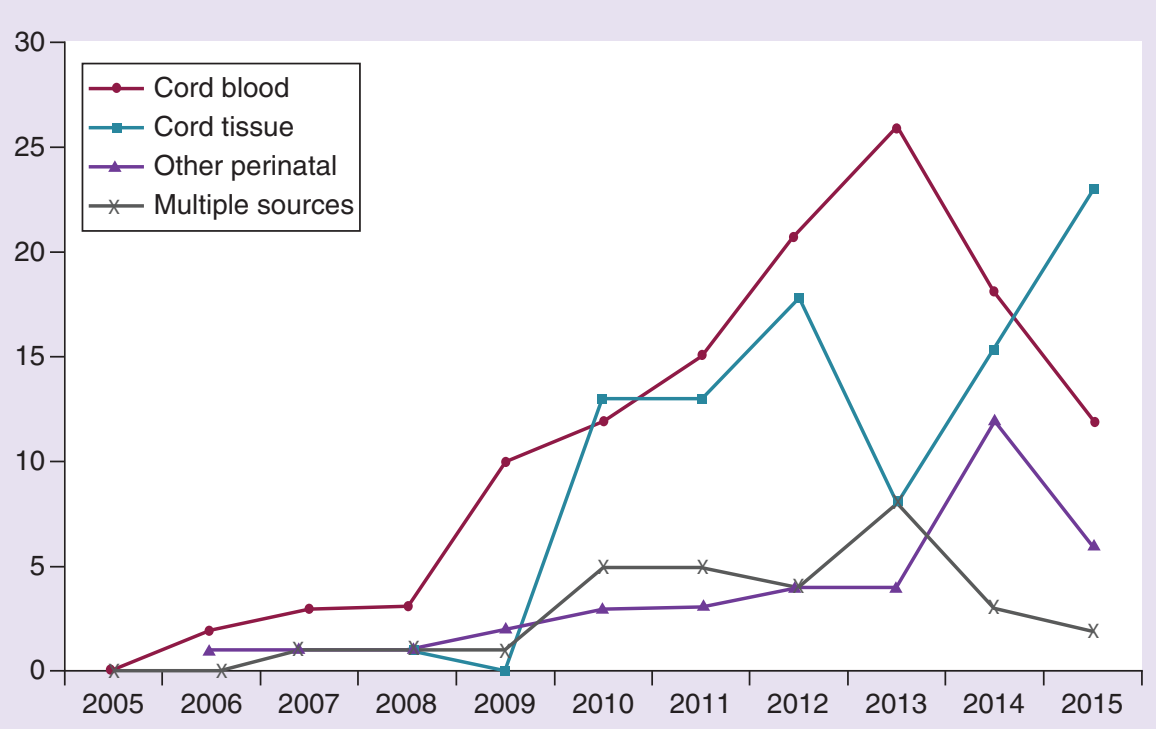

Figure 2. Number of advanced cell therapy clinical trials using perinatal cells registered per year, divided by the source of the cells: cord blood, cord tissue, other perinatal sources or multiple sources.

is perinatal. This method of characterizing trials, by source material, is often used by cord blood banks, because the source material has a direct correspondence to a product that they store and provide. When perinatal trials are viewed by source material, cord blood appears to be the dominant perinatal resource, either by cumulative fraction of the trials or by the number of annual trials for most years in this study.

However, characterizing perinatal trials purely by cell source can be misleading, because a single perinatal source can yield more than one cell type. We feel this is a very important theme of this field, and therefore we compare the trials breakdown by cell source versus cell type. Table 3 itemizes the number of trials per year for each of the cell types defined in our methodology section. Each trial was attributed to only one category so that the totals match the total number of trials.

Figure 3 shows the number of trials registered per year by cell type. This is a simplified graph in which all of the cell types in Table 3 that utilize MSC have been combined. When perinatal trials are characterized by cell type it becomes clear that the most popular use of perinatal sources is to harvest MSC. Over the past decade the majority of advanced cell therapy with perinatal cells, 53\%, utilized MSC derived from perinatal sources. Over 5 of the last 6 years in the study, trials with perinatal MSC comprised more than half the annual total, and in 2015 they reached $70 \%$ of the annual trials. Not only are all (100\%) of the trials from the source cord tissue utilizing the action of MSC, but $20 \%$ of the trials that utilize cord blood as cell source are isolating MSC, and there are additional trials with MSC cells from other perinatal sources. The cumulative use of cord blood cells that are not MSC is 35\%, with $23 \%$ from trials with unmanipulated cord blood that contains multiple cell types and $12 \%$ from trials that isolate and manipulate specific cells within cord blood. In summary, in this study cord blood is the most common cell source but MSC are the most popular cell type. The distinction between categorizing trials by cell source versus cell type leads to very different results, and future reports about perinatal cell therapy should be careful to specify their selection criteria.

Next we present figures that group the advanced cell therapy trials with perinatal cells by indication for use. In order to consolidate the numerous diagnoses treated in the perinatal trials into a list of reasonable length, we combined the trials into 19 groups of similar diagnoses. Supplementary Table 1 lists the originally specified indications for use versus the consolidated category. These trials cover all the major diseases of mankind identified by the WHO [45] and span the age range from premature birth to afflictions of old age. Some of these trials did not have a very specific indication for use, for example, many of the trials that perform transplants with manipulated cord blood cells are designed to recruit any high-risk hematologic malignancy. In defining the category of acquired neurologic disorders, we followed the prior practice of Sun et al. [46] to combine multiple types of brain injury that can occur near the time of birth. 
Table 3. Number of advanced cell therapy clinical trials using perinatal cells registered per year, divided by the cell type.

\begin{tabular}{|c|c|c|c|c|c|c|c|c|c|c|c|c|}
\hline \multirow[t]{2}{*}{ Cell type } & \multicolumn{12}{|c|}{ Trials/year } \\
\hline & 2005 & 2006 & 2007 & 2008 & 2009 & 2010 & 2011 & 2012 & 2013 & 2014 & 2015 & Total \\
\hline $\begin{array}{l}\text { Cord } \\
\text { blood allo } \\
\text { unmanip- } \\
\text { ulated }\end{array}$ & 0 & 1 & 1 & 1 & 2 & 3 & 8 & 6 & 8 & 6 & 5 & 41 \\
\hline $\begin{array}{l}\text { Cord } \\
\text { blood ma- } \\
\text { nipulated }\end{array}$ & 0 & 1 & 2 & 1 & 4 & 3 & 2 & 7 & 8 & 3 & 2 & 33 \\
\hline $\begin{array}{l}\text { Cord } \\
\text { blood MSC }\end{array}$ & 0 & 0 & 0 & 0 & 2 & 0 & 3 & 5 & 8 & 5 & 2 & 25 \\
\hline $\begin{array}{l}\text { Cord tissue } \\
\text { MSC }\end{array}$ & 0 & 0 & 0 & 1 & 0 & 13 & 13 & 18 & 8 & 16 & 23 & 92 \\
\hline $\begin{array}{l}\text { Other } \\
\text { perinatal } \\
\text { cells }\end{array}$ & 0 & 1 & 0 & 1 & 0 & 0 & 0 & 2 & 1 & 4 & 2 & 11 \\
\hline $\begin{array}{l}\text { Multiple } \\
\text { cell types }\end{array}$ & 0 & 0 & 1 & 1 & 1 & 3 & 3 & 3 & 8 & 3 & 1 & 24 \\
\hline Total & 0 & 3 & 5 & 6 & 13 & 33 & 36 & 47 & 46 & 49 & 43 & 281 \\
\hline
\end{tabular}

MSC: Mesenchymal stem/stromal cell.

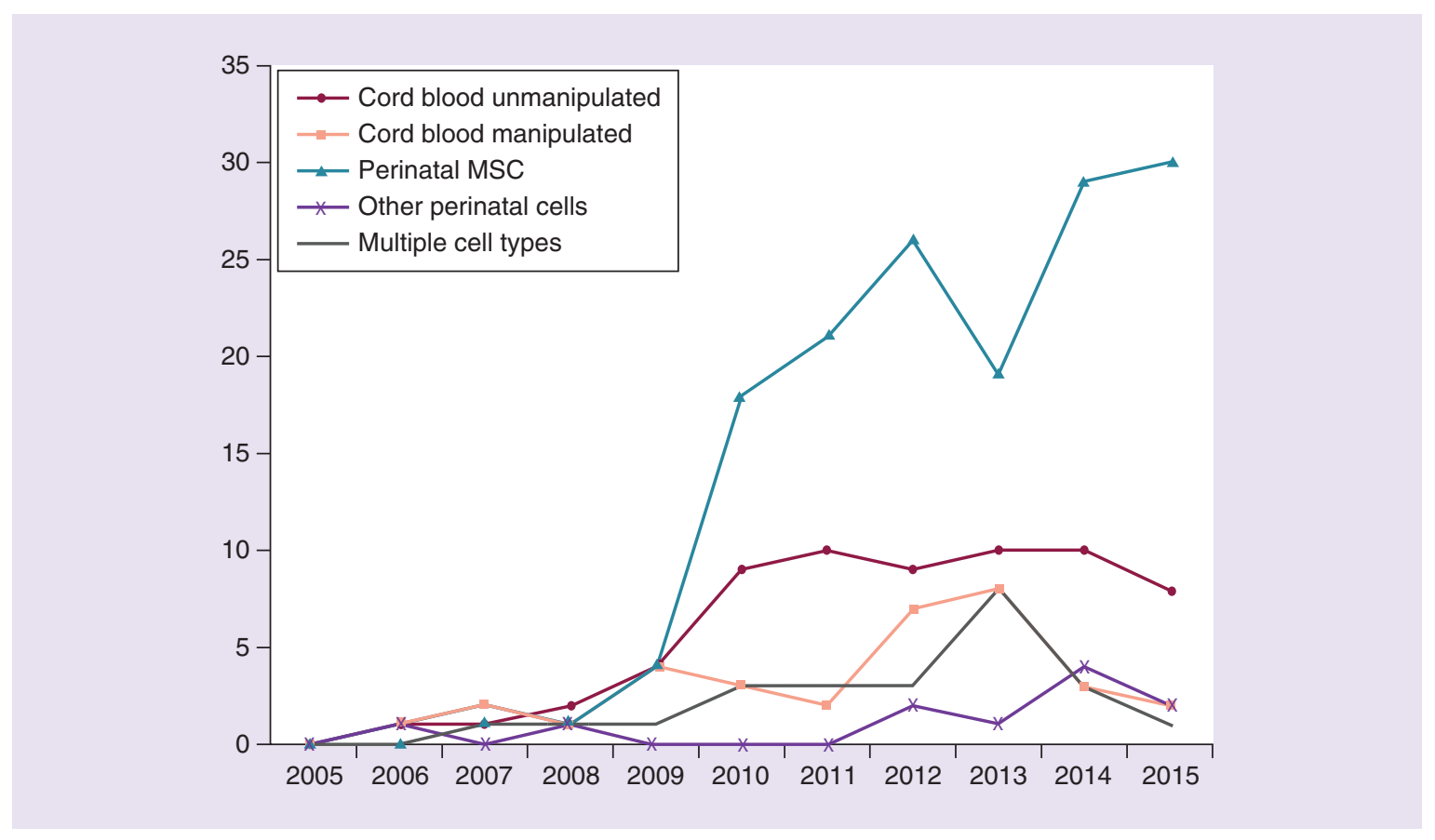

Figure 3. Number of advanced cell therapy clinical trials using perinatal cells registered per year, divided by the type of the cells: cord blood (not MSC) cells that are unmanipulated, cord blood (not MSC) cells that are manipulated, perinatal MSC, other perinatal cells or multiple sources. MSC: Mesenchymal stem cell. 


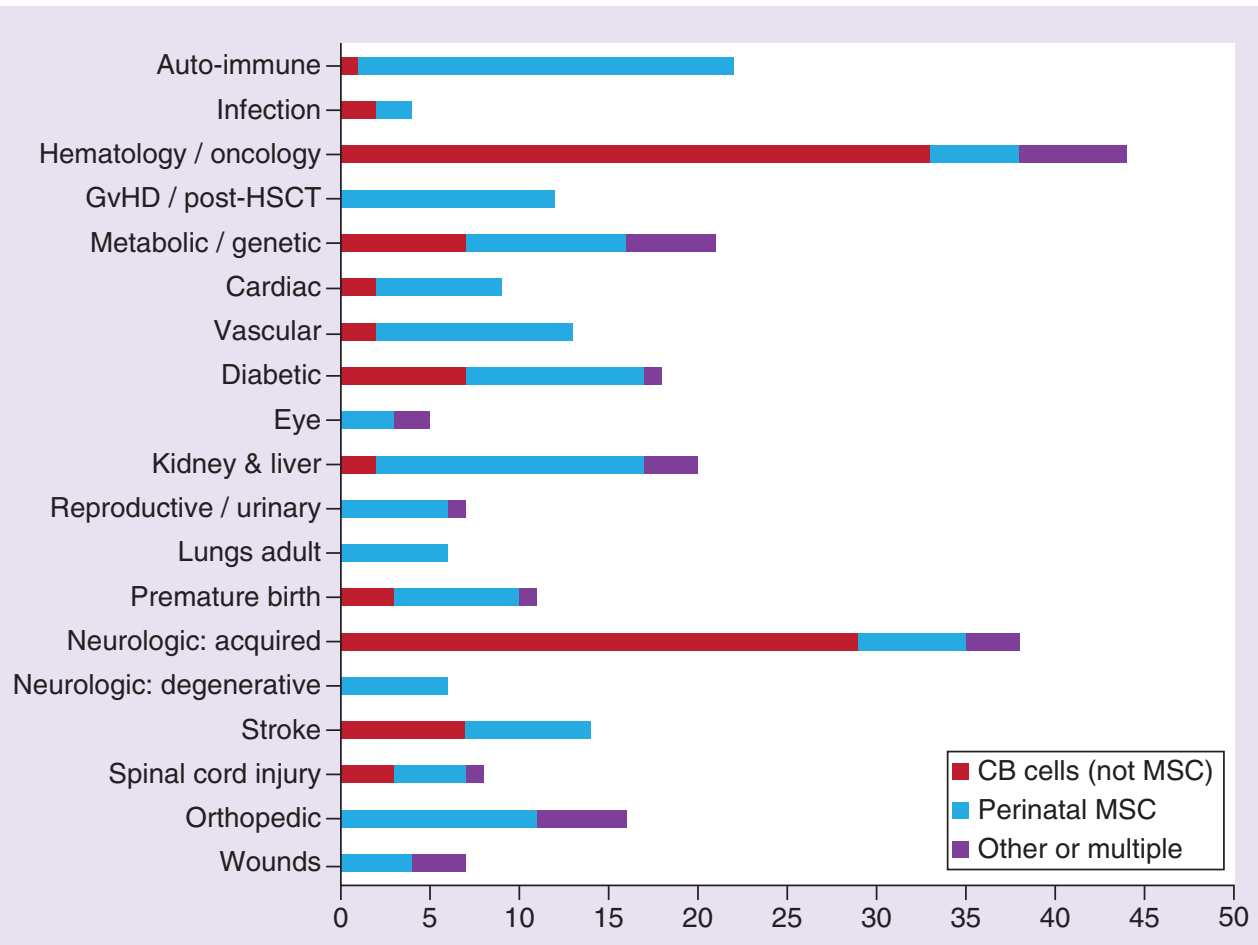

Figure 4. Number of advanced cell therapy clinical trials using perinatal cells registered in 2005-2015 are grouped into broad categories of indications for use and color coded by the cell type used in the therapy. CB: Cord blood; GvHD: Graft-versus-host disease; HSCT: Hematopoietic stem cell transplant; MSC: Mesenchymal stem/stromal cell.

Figure 4 is a column graph that shows the trials in diagnosis groups color coded by cell type: cord blood cells (not including MSC), perinatal MSC and other or multiple cell types. The most notable feature of this figure is that some conditions are primarily treated with one cell type or another. For example, 20 of 21 advanced cell therapy trials for autoimmune disorders employ MSC. Among the 97 trials that utilize cord blood cells other than MSC, 34\% target hematology/oncology disorders and 30\% target acquired neurologic disorders, so that these two categories account for the majority of advanced cell therapy with cord blood cells other than MSC. It is not at all surprising that cord blood, the primary perinatal source of HSC, is the dominant cell type used in therapies for hematology/oncology indications. But it is interesting that cord blood cells have only been trialed in 12 of the 19 broad diagnostic categories, whereas MSC have been trialed in every group. The breadth of diagnoses represented in this paper reflects the ease of obtaining perinatal MSC and the willingness of clinicians to attempt an early Phase trial with MSC for a wide variety of ailments, as well as their ability to do it in some regulatory environments.

Figure 5 repeats the same sorting of trials by diagnosis group but color codes the trials by the Phase of the clinical trial. It is quite obvious that advanced cell therapy with perinatal cells is a young field where the number of newly registered trials per year has not yet exceeded 50 and most of the trials are in early Phases. Overall, $83 \%$ of the perinatal trials in this decadal review are between Phases 0 /observational and II, only 6\% of the trials are in Phase II/III through IV, $2 \%$ are follow-up studies, and another $9 \%$ have unknown Phase. Only seven of the 19 diagnostic categories have trials in Phases II/III through IV. The top three indications with the highest fraction of Phase II/III through IV trials are wound healing at $29 \%$, spinal cord injury at $25 \%$ and metabolic and genetic disorders at $19 \%$.

Figure 6 once more repeats the same sorting of trials by diagnoses group, this time with the trials color coded by mode of cell administration. It was necessary to also group the modes of administration into global versus local categories, because the trials employed a variety of different modes of delivery. We chose to distinguish between trials that infuse cells into the patient's blood stream to circulate throughout the entire body, versus trials that deliver cells locally to a specific organ system by various methods, including topical administration as well as injections that are intrathecal, intramuscular, intratracheal, subretinal, among others. The mode of administration is not specified in $33 \%$ of the trial descriptions, but $47 \%$ are infusions into the circulation (either a vein or an artery or intraosseous), 


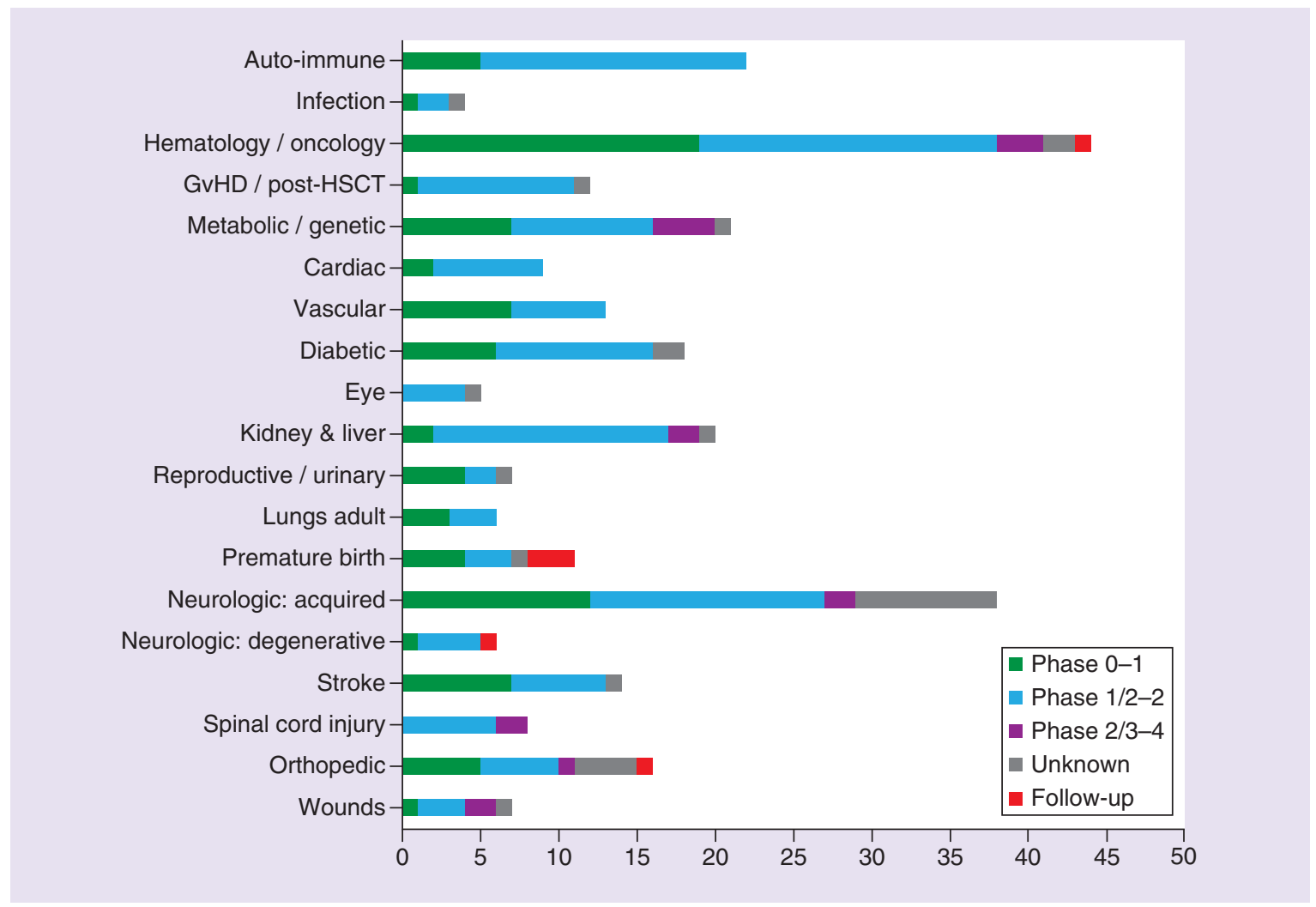

Figure 5. A number of advanced cell therapy clinical trials using perinatal cells registered in 2005-2015 are grouped into broad categories of indications for use and color coded by the Phase of the clinical trials.

GvHD: Graft-versus-host disease; HSCT: Hematopoietic stem cell transplant.

$18 \%$ are local administration and only $2 \%$ use multiple modes of delivery in one trial. The indications for use where more than half the trials employ local administration are: cardiac, vascular, reproductive systems of both women and men, bronchopulmonary dysplasia (premature lungs) and spinal cord injury.

Figure 7 is a pie chart that displays the trials in this study color coded by both geographic region and cell source. We selected this combination of parameters to display a very interesting feature of these data: over the past decade, only three countries have accounted for $79 \%$ of the advanced cell therapy with perinatal cells, and in each of those countries there is a preferred cell source, sometimes also a preferred cell type. Taken together, these trends mean that the majority of research in this field has fallen into selected categories of studies, pursued in specific geographic regions. The three countries that dominated the 281 trials of advanced cell therapy from perinatal sources are China (36\% trials), the USA (30\% trials) and South Korea (12\% trials).

In China, the leading type of advanced cell therapy with perinatal cells is trials that utilize MSC from cord tissue. China strongly dominates the world in this category, hosting $77 \%$ of all clinical trials that utilize cord tissue as a cell source. This dominance also illustrates the weakness of trial compilations that rely only on Clinicaltrials.gov to track clinical trials worldwide: in this decadal study $24 \%$ of the cord tissue trials in China were only registered on their national database Chinese Clinical Trial Registry (ChiCTR) and were not cross-posted to the US registry ClinicalTrials.gov. While China holds $36 \%$ of all perinatal trials, they hold the biggest fraction (44\%) of trials that are Phases II/III through IV.

In the USA, advanced cell therapy with perinatal cells is strong in the categories of both cord blood and other perinatal sources. The USA holds $41 \%$ of all clinical trials that utilize cord blood as a cell source. Among the USA trials that use cord blood as their cell source, $48 \%$ are researching manipulated cord blood cells, primarily to improve the performance of cord blood transplants for hematological malignancies. The USA also dominates the nascent field of advanced cell therapy with perinatal cells from sources other than cord blood or cord tissue; they are the only country that has more than five trials in this category and they hold $51 \%$ of the total clinical trials in this category. It is notable that while USA holds $38 \%$ of the trials that are Phases II/III through IV, all of their 


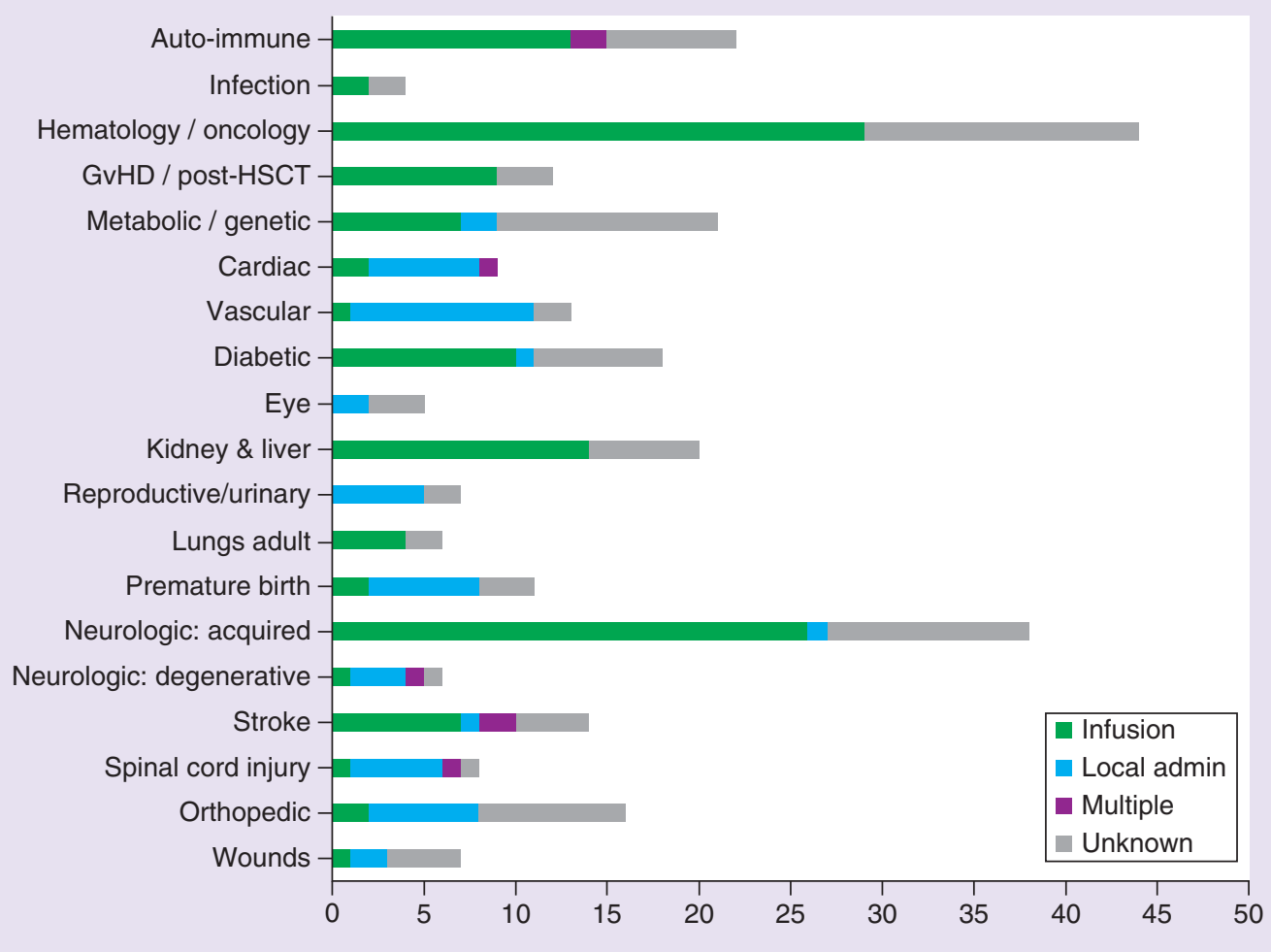

Figure 6. Number of advanced cell therapy clinical trials using perinatal cells registered in 2005-2015 are grouped into broad categories of indications for use and color coded by the mode of cell administration.

GvHD: Graft-versus-host disease; HSCT: Hematopoietic stem cell transplant.

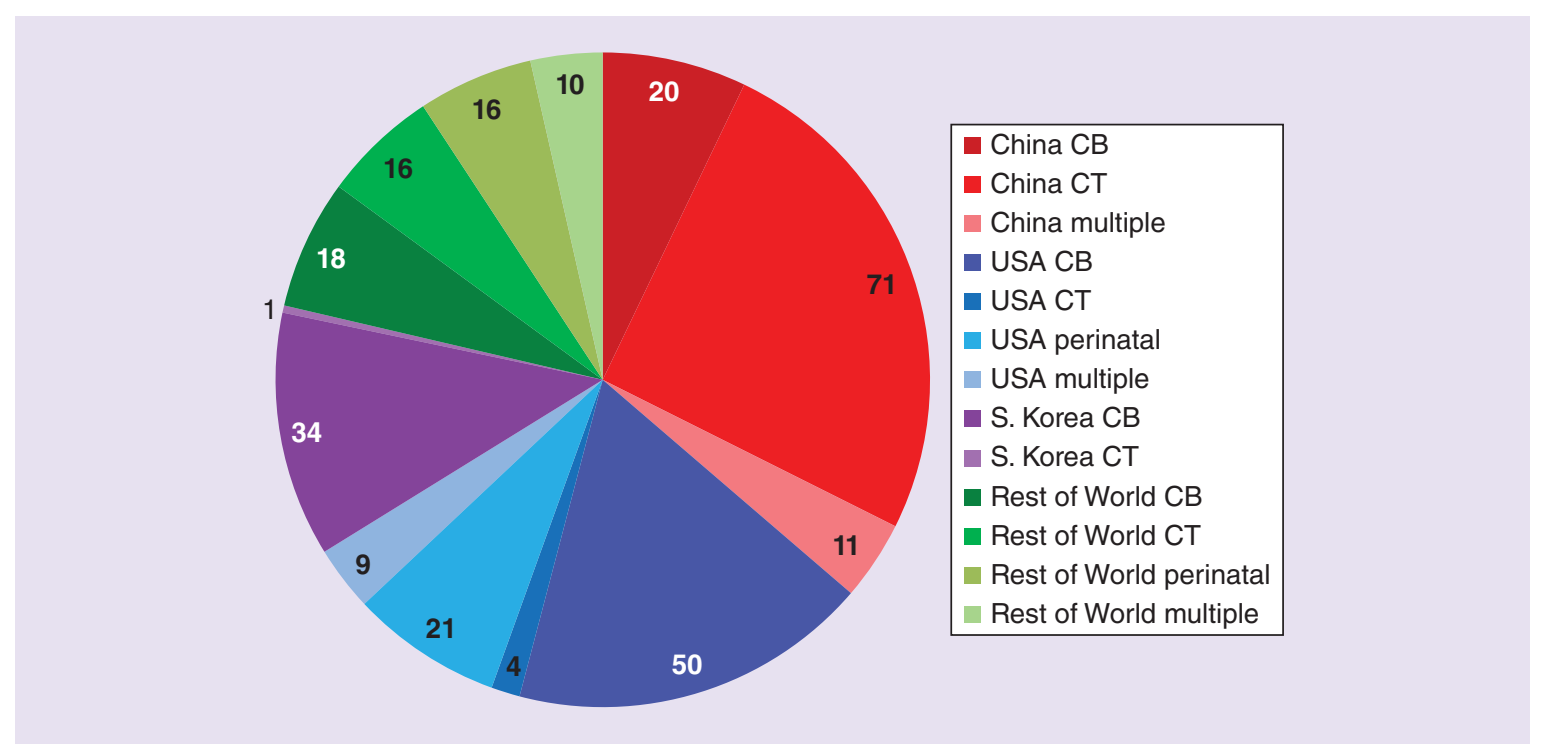

Figure 7. The advanced cell therapy trials with perinatal cells that were registered in 2005-2015 are color coded according to both geographic region and cell source. CB: Cord blood; CT: Cord tissue.

Phase IV trials are using 'other perinatal' cell sources for wound dressings. By comparison, the USA has very little cord tissue research, with only four trials over the decade in this study. 


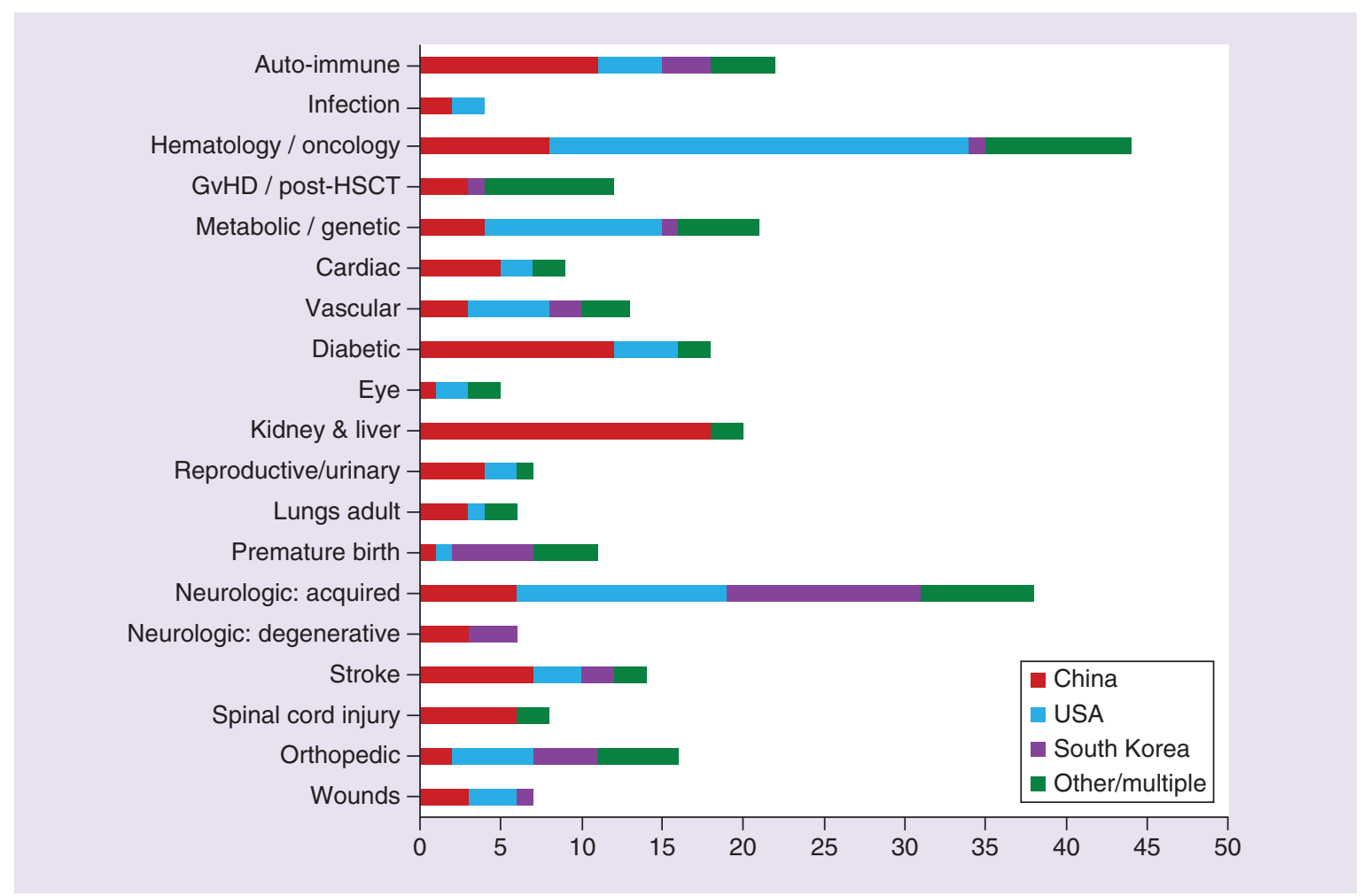

Figure 8. Number of advanced cell therapy clinical trials using perinatal cells registered in 2005-2015 are grouped into broad categories of indications for use and color coded by the country where the trial was registered. GvHD: Graft-versus-host disease; HSCT: Hematopoietic stem cell transplant.

In South Korea, advanced cell therapy with perinatal cells uses cord blood as the cell source almost exclusively (only one trial was not cord blood) and they hold $28 \%$ of all clinical trials with cord blood as cell source. However, the research paradigms in South Korea are very different from both China and the USA. Whereas the Chinese are leaders in trials that extract MSC from umbilical cord tissue, the South Koreans are leaders in extracting MSC from cord blood. They hold $80 \%$ of all trials with MSC extracted from cord blood. In fact, an additional two trials in the USA that use MSC from cord blood are sponsored by Medipost of South Korea, so we could say they are responsible for $88 \%$ of trials with this combination of cell type and source.

Having identified the three countries that dominate advanced cell therapy with perinatal cells, and explained the preferred cell sources and cell types in each country, Figure 8 again shows a column graph of the trials grouped into broad indications for use, this time with the trials color coded by the region where the trial is registered. Based on the national preferences described (Figure 7), it is not surprising that the indications which are primarily treated with MSC tend to correspond to trials in China, whereas the indications which are primarily treated with cord blood tend to correspond to trials in the USA and South Korea. The top three indications where the trials are primarily in China are liver diseases $(90 \%)$, spinal cord injury $(75 \%)$ and diabetes $(67 \%)$; following these three are several indications where China has close to half the clinical trials. The USA has half or more of the trials for the indications hematology/oncology (59\%) and metabolic/genetic (52\%). South Korea has close to half the trials for degenerative neurological disorders $(50 \%)$ and premature birth $(45 \%)$. The only indication where the research is fairly evenly distributed between the four geographic regions, with each region holding between 15 and 35\% of the trials, is acquired neurological disorders: $16 \%$ in China, 34\% in the USA, 32\% in South Korea and 18\% in other or multiple countries.

Figure 9 is a column graph of trial enrollment versus diagnosis group, not trial numbers, and the columns are color coded by the region where the trial is registered. Several caveats are required to interpret this graph of target enrollment by diagnosis and nation. One caveat is that not all trials reach their target enrollment before closing. Another caveat is that not all patients in a trial receive advanced cell therapy. In very early Phase trials, especially safety studies, all patients receive the tested therapy. But the hallmark of later Phase trials is the existence of control 


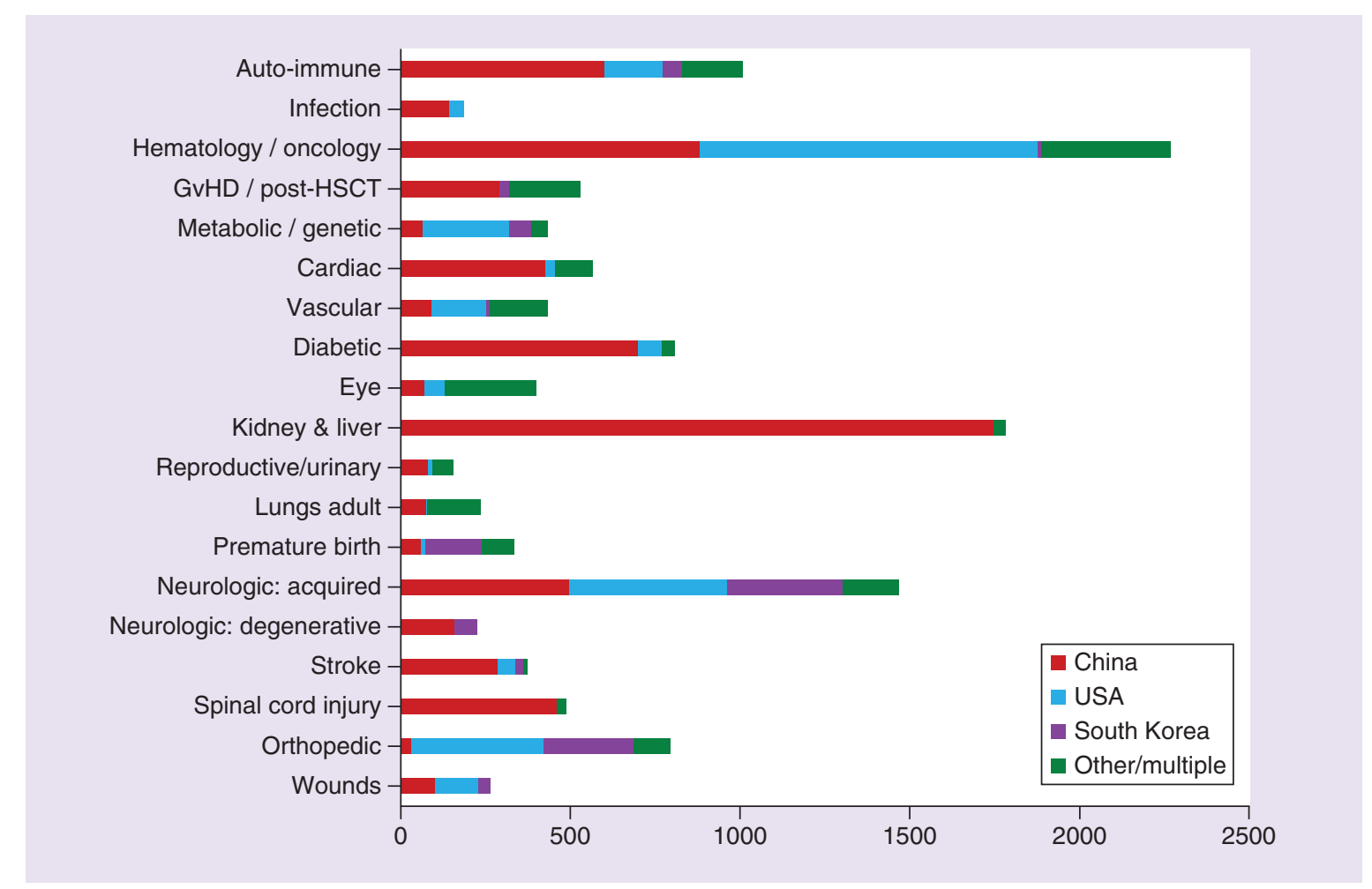

Figure 9. Target enrollment of advanced cell therapy clinical trials using perinatal cells registered in 2005-2015 are grouped into broad categories of indications for use and color coded by the country where the trial was registered. GvHD: Graft-versus-host disease; HSCT: Hematopoietic stem cell transplant.

groups who either do not receive the tested therapy or receive it after a time delay. Hence the numbers in these groups are an upper limit to how many patients may have received advanced cell therapy for these indications. The total of all the target enrollments for the first decade of advanced cell therapy trials with perinatal cells is 12,739 patients. The four enrollment groups that exceed 1000 patients are hematology/oncology (2269), kidney and liver (1781), neurologic: acquired (1468) and autoimmune (1006).

An additional bias in the interpretation of Figure 9 is national trends. The average target enrollment of clinical trials in this study is 66 in China, 34 in the USA, 30 in South Korea and 34 in other nations. Among the five biggest trials, four are in China and the fifth is multinational. Among the 36 trials that seek to enroll 100 patients or more, 61\% are in China. Because trials in China tend to be twice as large as trials elsewhere, any diagnosis or treatment modality that is popular in China will receive a disproportionate number of patients. Hence liver disorders are the second biggest patient enrollment group, even though trials for that indication only represent seven percent of the trials in this study. Overall, China holds $36 \%$ of the trials in this decadal study but $53 \%$ of the target enrollment.

Figure 10 displays the fraction of trials sponsored by academia versus industry on an annual basis. Over the 2005-2015 decade, 110 clinical trials of advanced cell therapy with perinatal cells were sponsored by 33 companies in 11 countries [47]. The fraction of trials sponsored by industry was $23 \%$ in China, $51 \%$ in the USA and $60 \%$ in South Korea. The only other nationality where companies have sponsored more than ten trials of advanced cell therapy with perinatal cells is Israel, but many of those trials are being conducted in multiple other countries, so they cannot be treated as a percentage of trials in Israel. During the second half of the decadal study, the percentage of trials sponsored by industry was consistently around $40 \%$ worldwide.

This study reviews advanced cell therapy with perinatal cells during the decade 2005-2015, but the labor required to prepare and analyze these data took place over a year. Meanwhile, the status of trials in this study has continued to evolve with time. Figure 11 is a pie chart that captures the status of these 281 trials as of 31 July 2017. The majority of the trials (61\%) are either completed or are still active (enrolling or active but not enrolling). Only $12 \%$ of the trials have fallen by the wayside, with a status of either withdrawn or suspended or terminated. Unfortunately $27 \%$ of the trials have not updated their status, so their fate is unknown. Bear in mind that the last 4 years of the 


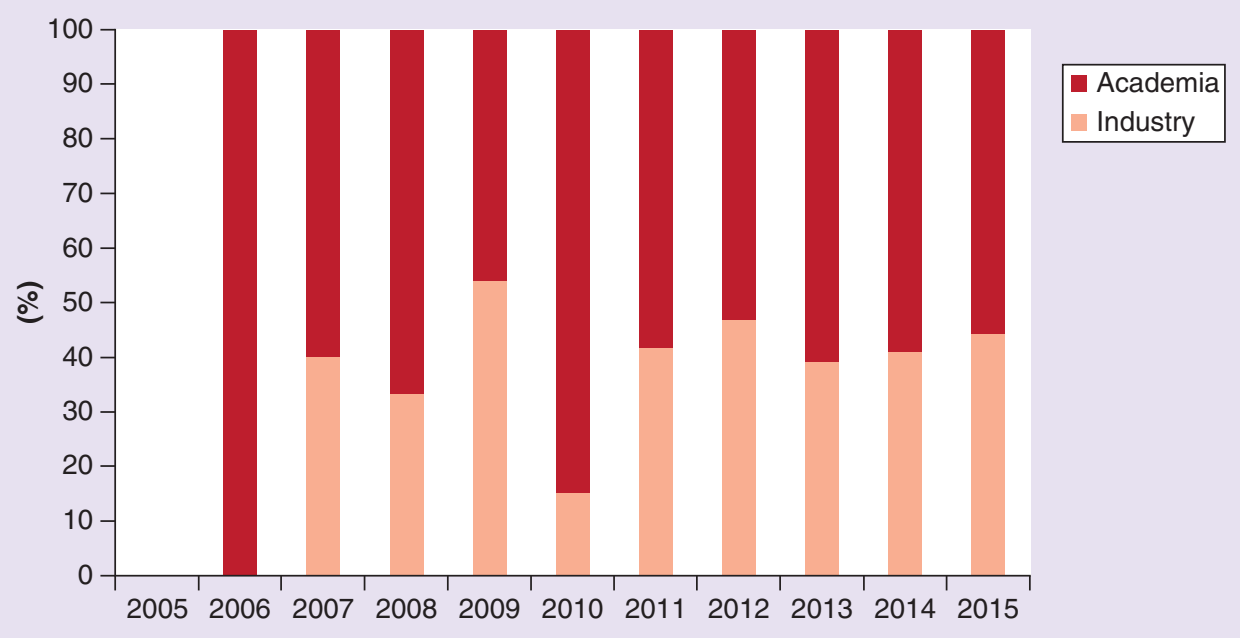

Figure 10. Number of advanced cell therapy clinical trials using perinatal cells registered per year, color coded by industry or academic sponsorship.

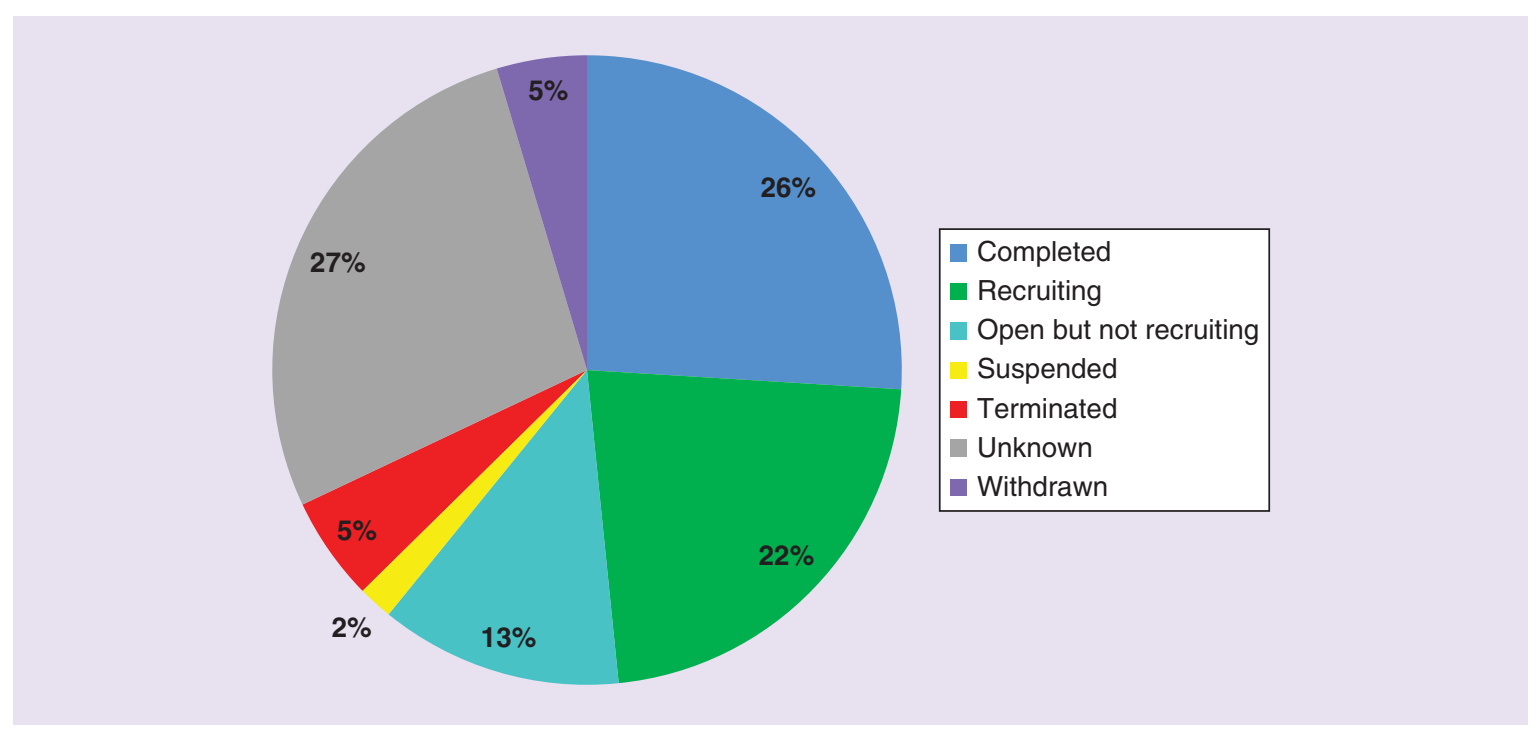

Figure 11. Status of the $\mathbf{2 8 1}$ advanced cell therapy clinical trials using perinatal cells that were registered in 2005-2015, as of 31 July 2017.

study account for $66 \%$ of the registered trials, so it is not that surprising that so many trials (35\%) are still open. Plus, it is not unusual for certain types of trials with perinatal cells to run for years. One factor is that the $8 \%$ of trials that use autologous cord blood mostly recruit patients from private banks, and it takes them longer to reach the target enrollment of patients who both have the diagnosis and also have privately stored cord blood. Another factor is that the $7 \%$ of trials that treat genetic and metabolic conditions are by definition trying to accrue patients with rare disorders.

The dawn of regenerative medicine with perinatal cells is usually attributed to the first use of cord blood stem cells as therapy for cerebral palsy [20]. Given those origins of the field, it is worthwhile to take a deeper look at the trials for acquired neurological disorders. Dr Kurtzberg's group at Duke University in the USA observed that children who received cord blood transplants for metabolic disorders had remarkable improvements in cognitive development [48-50]. Based on that observation, in 2005 they began treating children diagnosed with cerebral palsy and other acquired neurological disorders with autologous cord blood, provided the patient's personal cord 
blood was available in storage. A retrospective safety study of the first 184 patients was published in 2010 [46]. However a very important caveat about this protocol, is that while it inspired cord blood trials around the world, nonetheless during the first few years all of the patients were treated under a compassionate use exemption and no clinical trial was registered. The first USA trial using autologous cord blood for regenerative therapy of an acquired neurological disorder was registered in 2008 for hypoxic-ischemic encephalopathy (HIE, NCT00593242), and the next two trials were registered for cerebral palsy in 2010 (NCT01072370, NCT01147653). The first US trial to treat cerebral palsy with allogeneic cord blood was registered in 2015 (NCT02599207). By comparison, in South Korea all advanced cell therapy for cerebral palsy has always been with allogeneic cord blood since the first registered trial in 2010 (NCT01193660). The ability to use allogeneic cells has enabled trials in South Korea to accrue patients much faster than the autologous trials in the USA, and the first publications that demonstrate the efficacy of perinatal cell therapy for cerebral palsy against control groups are from the South-Korea research pipeline [51-53]. This history illustrates that even the most thorough compilation of registered trials will still miss important emerging research that has not been registered, either because the trial is Phase I, or the host country does not require international trial registration, or the patients are treated under a compassionate exemption.

\section{Conclusion}

We have conducted a complete international screen of the 281 clinical trials registered between 2005 and 2015 that used cells from perinatal sources for advanced cell therapy. We believe this is the most complete and detailed analysis of clinical trials in this field to date, and the data available have enabled us to identify a few notable trends.

The single most important point we wish to make for future researchers in this field is that they must specify whether their selection criteria are cell sources or cell types, because these choices lead to different results. When the trials in this decadal study are categorized by cell source, we find that the largest group is $43 \%$ of the trials utilize cord blood as the source material. However, $20 \%$ of the trials with cord blood as source are utilizing cord blood to extract MSC. When the trials are categorized by the cell type that is believed to provide the mechanism of action, we see that $53 \%$ of the trials are utilizing MSC derived from various perinatal sources.

Throughout this study we tried to explore the breakdown of trial parameters versus the indication being treated with advanced cell therapy. Because the trials cover a broad spectrum of diagnostic conditions, we were forced to group them into consolidated categories that are listed in Supplementary Table 1. We found that $64 \%$ of the trials that utilize cord blood cells (other than MSC) are targeting either hematology/oncology disorders or acquired neurologic disorders. The variety of conditions included in this data are driven by a large number of early Phase trials testing perinatal MSC for many conditions. Overall, $83 \%$ of the advanced cell therapy trials with perinatal cells are between Phases 0 /observational and II. The mode of cell administration is local for only $18 \%$ of trials.

The trials in this decadal study demonstrate major trends with nationality. Three countries account for $79 \%$ of the trials: China, the USA and South Korea. Researchers in each of those countries tend to prefer specific cell sources and cell types. The target enrollment of clinical trials in China is roughly twice as large as other countries, so that China holds $36 \%$ of the perinatal trials in this study but $53 \%$ of the target enrollment. Worldwide, the fraction of these trials sponsored by industry is $39 \%$, but industry supports over half of the trials in selected countries where a handful of companies have registered multiple trials. We believe that our historic analysis of clinical trials performing advanced cell therapy with perinatal cells may help to predict future market growth and investment.

\section{Future perspective}

We have seen that advanced cell therapy with perinatal cells has grown to involve researchers from different countries using different approaches. Moreover, corporate sponsors have invested in this work. Regenerative medicine with cord blood began in 2005, and trials with cord tissue MSC took off in 2009. At present we are experiencing a third wave of growth from trials that use placental cells and the amniotic membrane of the placenta. We anticipate that the next edition of this study should capture more trials using cells from these perinatal sources, especially for the indications of wound healing and orthopedic therapy. Meanwhile, collaborations that are developing hematology/oncology therapies from manipulated cord blood cells are continuing to make progress down the trial Phase pipeline, despite competition from new chimeric antigen receptor T-cell therapies. It remains to be seen how the oncology space eventually determines the most effective therapies from the alphabet soup of manipulated cell types that can be incorporated into cancer immunotherapy. Whichever cell type combinations are the most effective, donated cord blood units will be a potential choice to develop a universal donor therapy. We predict that therapies for inflammation that are based on perinatal MSC will be approved by regulatory bodies in several countries, 
probably starting with South Korea. While banking of perinatal cells tends to be a local or regional business, anyone who seeks to develop international therapies with perinatal cells should keep an eye on the development of trials in China.

\section{Executive summary}

Background

- We have compiled a database of 281 clinical trials registered in 2005-2015 that performed advanced cell therapy with cells of perinatal origin.

Methodology

- This is the first cumulative review of the field of advanced cell therapy with perinatal cells, as well as the first analysis that tracks perinatal trials by year of trial registration.

- These are the most complete data available for this time period because we searched all international trial registries, not just ClinicalTrials.gov.

Results \& discussion

- The majority of trials in this study, $88 \%$, are performing 'regenerative medicine', and the rest are treatments of hematologic malignancies with manipulated cells.

- Over the past decade, the three countries China, the USA and South Korea contributed $79 \%$ of the registered trials in advanced cell therapy with perinatal cells, and in each of those countries researchers tend to work with a preferred cell source and cell type.

\section{Conclusion}

- It is important for studies in this field to distinguish between cell source versus cell type when characterizing cell therapy clinical trials.

- Cumulatively the most common source of perinatal cells for advanced cell therapy trials is cord blood, but the cell type that provides the mechanism of action in the majority of trials is mesenchymal stem/stromal cells.

Future perspective

- In this arena, the strongest growth area for the next decade will be advanced cell therapy with cells from the placenta and amniotic membrane.

\section{Supplementary data}

To view the supplementary data that accompany this paper please visit the journal website at: www.futuremedicine.com/doi/suppl/10.2217/rme-2017-0066

Financial \& competing interests disclosure

The authors have no relevant affiliations or financial involvement with any organization or entity with a financial interest in or financial conflict with the subject matter or materials discussed in the manuscript. This includes employment, consultancies, honoraria, stock ownership or options, expert testimony, grants or patents received or pending, or royalties.

No writing assistance was utilized in the production of this manuscript.

\section{Open access}

This work is licensed under the Attribution-NonCommercial-NoDerivatives 4.0 Unported License. To view a copy of this license, visit http://creativecommons.org/licenses/by-nc-nd/4.0/

\section{References}

Papers of special note have been highlighted as: $\bullet$ of interest

1. Broxmeyer HE, Douglas GW, Hangoc G et al. Human umbilical cord blood as a potential source of transplantable hematopoietic stem/progenitor cells. Proc. Natl Acad. Sci. USA 86(10), 3828-3832 (1989).

2. Broxmeyer HE, Srour E, Orschell C et al. Cord blood stem and progenitor cells. Meth. Enzymol. 419, 439-473 (2006).

3. Sarugaser R, Lickorish D, Baksh D, Hosseini MM, Davies JE. Human umbilical cord perivascular (HUCPV) cells: a source of mesenchymal progenitors. Stem Cells 23(2), 220-229 (2005).

4. Secco M, Zucconi E, Vieira NM et al. Multipotent stem cells from umbilical cord: cord is richer than blood! Stem Cells 26(1), 146-150 (2008).

5. Schugar RC, Chirieleison SM, Wescoe KE et al. High harvest yield, high expansion, and phenotype stability of CD146 mesenchymal stromal cells from whole primitive human umbilical cord tissue. J. Biomed. Biotechnol. 2009, 1-11 (2009). 
6. Hodges RJ, Lim R, Jenkin G, Wallace EM. Amnion epithelial cells as a candidate therapy for acute and chronic lung injury. Stem Cells Int. 2012, 1-7 (2012).

7. Zhu D, Wallace EM, Lim R. Cell-based therapies for the preterm infant. Cytotherapy 16(12), 1614-1628 (2014).

8. Lim IJ, Phan TT. Epithelial and mesenchymal stem cells from the umbilical cord lining membrane. Cell Transplant. 23(4), 497-503 (2014).

9. Anthrogenesis Corp US: WO2007079183 A3 (2006).

10. Soncini M, Vertua E, Gibelli L et al. Isolation and characterization of mesenchymal cells from human fetal membranes. J. Tissue Eng. Regen. Med. 1(4), 296-305 (2007).

11. Parolini O, Soncini M, Evangelista M, Schmidt D. Amniotic membrane and amniotic fluid-derived cells: potential tools for regenerative medicine? Regen. Med. 4(2), 275-291 (2009).

12. Serikov V, Hounshell C, Larkin S et al. A brief communication: human term placenta as a source of hematopoietic cells. Exp. Biol. Med. (Maywood) 234(7), 813-823 (2009).

13. Zhu Y, Yang Y, Zhang Y et al. Placental mesenchymal stem cells of fetal and maternal origins demonstrate different therapeutic potentials. Stem Cell Res. Ther. 5(2), 48 (2014).

14. Perinatal Stem Cells. Cetrulo CL, Cetrulo KJ, Cetrulo CL (Eds). John Wiley \& Sons Inc, NJ, USA (2009).

- The very first review book dedicated to perinatal stem cells, with editing led by Curtis L Cetrulo MD FACOG, who has been saying for over a decade, "everyone is or should be interested in the placenta."

15. Perinatal Stem Cells (2nd Edition). Cetrulo KJ, Cetrulo CL, Taghizadeh RR (Eds). John Wiley \& Sons Inc, NJ, USA (2013).

- Second review book about perinatal stem cells from the Cetrulo team.

16. Perinatal Stem Cells (Volume 1). Atala A, Murphy S (Eds). Springer-Verlag, NY, USA (2014).

- Review book about perinatal stem cells from the Atala team at Wake Forest University.

17. Gluckman E, Broxmeyer HE, Auerbach AD et al. Hematopoietic reconstitution in a patient with Fanconi's anemia by means of umbilical-cord blood from an HLA-identical sibling. N. Engl. J. Med. 321(17), 1174-1178 (1989).

18. Gluckman E, Ruggeri A, Volt F, Cunha R, Boudjedir K, Rocha V. Milestones in umbilical cord blood transplantation. Br. J. Haematol. 154(4), 441-447 (2011).

19. Ballen KK, Verter F, Kurtzberg J. Umbilical cord blood donation: public or private? Bone Marrow Transplant. 50(10), 1271-1278 (2015).

20. Cord Blood Registry. Experimental therapy for brain injury. www.cordblood.com/benefits-cord-blood/our-clients-their-stories/cord-blood-banking-reviews/anoxic-brain-injury

21. Regulation (EC) No 1394/2007 of the European Parliament and of the Council of 13 November 2007 on advanced therapy medicinal products and amending Directive 2001/83/EC and Regulation (EC) No 726/2004 (2007). http://ec.europa.eu/health/sites/health/files/files/eudralex/vol-1/reg_2007_1394/reg_2007_1394_en.pdf

22. US FDA. FDA regulation of human cells, tissues, and cellular and tissue-based products (HCT/P's) product list. www.fda.gov/BiologicsBloodVaccines/TissueTissueProducts/RegulationofTissues/ucm150485.ht

23. Regenerative medicine glossary. Regenerative Medicine 4(4s), S1-S88 (2009).

24. Mason C, Manzotti E, Culme-Seymour EJ. Cell \& gene therapy, and regenerative medicine - different definitions. Cell Gene Ther. Ins. 2(2), 141-145 (2016).

- The editorial is an important guidepost for clarifying what constitutes 'regenerative medicine'.

25. Beitzel K, Allen D, Apostolakos J et al. US definitions, current use, and FDA stance on use of platelet-rich plasma in sports medicine. J. Knee Surg. 28(1), 029-034 (2014).

26. Kurtzberg J, Buntz S, Gentry T et al. Preclinical characterization of DUOC-01, a cell therapy product derived from banked umbilical cord blood for use as an adjuvant to umbilical cord blood transplantation for treatment of inherited metabolic diseases. Cytotherapy 17(6), 803-815 (2015).

27. Kita K, Gauglitz GG, Phan TT, Herndon DN, Jeschke MG. Isolation and characterization of mesenchymal stem cells from the sub-amniotic human umbilical cord lining membrane. Stem Cells Dev. 19(4), 491-502 (2010).

28. Liao Y, Ivanova L, Plumer T et al. Potential use of human placenta derived stem cell (HPDSCs) as a novel stem cell source for the treatment of recessive dystrophic epidermolysis bullosa (RDEB). Biol. Blood Marrow Transplant. 22(3), S422-S423 (2016).

29. Flower AM, Nash M, Minzer S. A pilot trial of unmatched human placenta-derived stem cells (HPDSCs) in conjunction with unrelated cord blood transplantation (UCBT) in children and young adults with malignant and non-malignant disease (IND 14949). Biol. Blood Marrow Transplant. 22, S19-S481 (2016).

30. CellTrials.org. https://celltrials.org/

- The landing page of this website provides a table comparing every compilation of clinical trials published to date.

31. Iafolla MAJ, Tay J, Allan DS. Transplantation of umbilical cord blood-derived cells for novel indications in regenerative therapy or immune modulation: a scoping review of clinical studies. Biol. Blood Marrow Transplant. 20(1), 20-25 (2014). 
32. Clinicaltrials.gov trends page. https://clinicaltrials.gov/ct2/resources/trends

33. Japan's UMIN clinical trial registry (UMIN-CTR). www.umin.ac.jp/english/history.htm

34. ClinicalTrials.gov. https://clinicaltrials.gov/ct2/about-site/background

35. Japan medical association clinical trial registry (JMA-CTR). www.jmacct.med.or.jp/en/about/jmacct.html

36. EU clinical trials register (EudraCT). www.clinicaltrialsregister.eu/about.html

37. Chinese clinical trial registry (ChiCTR). www.chictr.org.cn/abouten.aspx

38. WHO (ICTRP). www.who.int/ictrp/about/en/

39. Netherlands trial register (NTR). www.trialregister.nl/trialreg/index.asp

40. Australian New Zealand clinical trial registry (ANZCTR). www.anzctr.org.au/Support/AboutUs.aspx

41. Clinical trials registry-India (CTRI). http://ctri.nic.in/Clinicaltrials/

42. German clinical trials register (DRKS). www.drks.de/drks_web/navigate.do?navigationId=start\&messageDE=Home\&messageEN=Home

43. Iranian registry of clinical trials (IRCT). www.irct.ir/

44. Research information service from South Korea (CRiS). https://cris.nih.go.kr/cris/en/board/board_view.jsp?board_seq=8\&pageNum=1\&article_type=\&article_seq=2472.

45. WHO. Top 10 causes of death worldwide-2015. www.who.int/mediacentre/factsheets/fs310/en/

46. Sun J, Allison J, McLaughlin C et al. Differences in quality between privately and publicly banked umbilical cord blood units: a pilot study of autologous cord blood infusion in children with acquired neurologic disorders. Transfusion. 50(9), 1980-1987 (2010).

47. Parent's guide to cord blood foundation. Growing use of newborn stem cells in clinical trials (2017). https://parentsguidecordblood.org/en/news/growing-use-newborn-stem-cells-clinical-trials

48. Prasad VK, Kurtzberg J. Emerging trends in transplantation of inherited metabolic diseases. Bone Marrow Transplant. 41(2), 99-108 (2008).

49. Prasad VK, Mendizabal A, Parikh SH et al. Unrelated donor umbilical cord blood transplantation for inherited metabolic disorders in 159 pediatric patients from a single center: influence of cellular composition of the graft on transplantation outcomes. Blood 112(7), 2979-2989 (2008).

50. Prasad VK, Kurtzberg J. Umbilical cord blood transplantation for non-malignant diseases. Bone Marrow Transplant. 44(10), 643-651 (2009).

51. Min K, Song J, Kang JY et al. Umbilical cord blood therapy potentiated with erythropoietin for children with cerebral palsy: a double-blind, randomized, placebo-controlled trial. Stem Cells 31(3), 581-591 (2013).

52. Kang M, Min K, Jang J et al. Involvement of immune responses in the efficacy of cord blood cell therapy for cerebral palsy. Stem Cells Dev. 24(19), 2259-2268 (2015).

53. Sun JM, Song AW, Case LE, et al. Effect of autologous cord blood infusion on motor function and brain connectivity in young children with cerebral palsy: a randomized, placebo-controlled trial. Stem Cells Transl. Med. doi:10.1002/sctm.17-0102 (2017) (Epub ahead of print). 